\title{
Acoustic Neuroma Related Eye Involvement and Its Treatment
}

\author{
Akustik Nörinoma İle İlişkili Göz Tutulumu Ve Tedavisi \\ Tuğba Göncü ${ }^{1}$, Sevin Çakmak ${ }^{1}$, Fatih Mehmet Adıbelli ${ }^{1}$, Ali Akal ${ }^{1}$, Mehtap Kocatürk ${ }^{2}$ \\ ${ }^{1}$ Harran Üniversitesi Tıp Fakültesi, Göz Hastalıkları Ana Bilim Dalı, Şanlıurfa \\ ${ }^{2}$ Harran Üniversitesi Tıp Fakültesi, Nöroloji Ana Bilim Dalı, Şanlıurfa
}

Dergiye Ulaşma Tarihi: 30/04/2015 Dergiye Kabul Tarihi: 23/07/2015 DOI: 10.5505/aot.2016.5238

\begin{abstract}
ÖZET
Akustik nörinom, vestibulokohlear sinirin vestibüler kısmından köken alan serebellopontin açıda en sık rastlanan iyi huylu bir tümördür. Kırk altı yaşında kadın hasta sağ göz kapağını kapatamama, dışa bakamama şikayetleriyle kliniğimize başvurdu. Beş yıl önce akustik nörinom nedeniyle ameliyat geçirdiği öğrenilen hastanın yapılan muayenesinde sağ periferik fasiyal paralizisi, ezotropya, sağ dışa bakış kısıtlılığı ve korneada his kaybı tespit edildi. Hastaya fasiyal sinir felci bulgularını düzeltmek için orta yüz kaldırma ve levator menteşe yöntemi ile levator geriletme ameliyatı yapıldı. Abdusens felci için ise Foster sütür ile Hummelsheim split tendon transpozisyonu uygulandı. Ameliyat sonrası bulgularında belirgin düzelme izlendi. Bu olguda akustik nörinom cerrahisi sonrası ortaya çıkan göz şikayetlerine yaklaşım tartışıldı.
\end{abstract}

Anahtar Kelimeler: akustik nörinom, kranyal sinir felci, fasiyal paralizi, abdusens paralizi

\section{ABSTRACT}

Acustic neuroma is the most common bening tumor of cerebellopontine angle which is originated from vestibular portion of the vestibulocochlear nerve. Fourty-Six year-old female patient was admitted to our clinic with complaints of inability to close her right eye. She had history of a acustic neuroma operation 5 years ago. Her ophthalmic examination revealed right peripheral facial paralysis, right esotropia, underactivity of the left lateral rectus muscle and impaired corneal sensation. Therefore, mid-face lift combined with levator hinge procedure was performed for facial nerve paralysis. Hummelsheim split tendon transfer with Foster modification was performed for abducens paralysis. After these procedures, a satisfactory result was achieved. In this report, acoustic neuroma related eye involvement and its treatment was discussed.

Key words: Acustic neuroma, cranial nerve palsies, facial paralysis, abducens paralysis

\section{Giriş}

Akustik nörinom, vestibulokohlear sinirin vestibüler kısmının k1lıfındaki myelin k1lıf hücrelerinden köken alan iyi huylu bir tümördür. Vestibüler şvannom daha doğru ifade eden bir tanımlamadır (1). Epidemiyolojik çalışmalarda, insidansı 1$1.5 / 100.000$ olarak bildirilmektedir (1). Serebellopontin açıda en sik görülen tümör olup bu lezyonların \%75-90'ın1 oluşturmaktadır $(2,3)$. Vestibulokohlear sinirin etkilenmesi ya da komşu beyin sapı bölümüne bası sonucu klinik bulgular oluşmaktadır. İlerleyici nörosensoriyal işitme kaybı, baş dönmesi, çınlama en sık başvuru şikayetleridir $(1,4)$. Tümör boyutları arttıkça temporal kemiği harabiyete uğratır ve büyüyen tümör internal akustik kanalı doldurur. Zamanla internal akustik meadan çıkarak koklear sinir, trigeminal sinir, fasiyal sinir ve komşu beyin sap1 ve beyinciğe bas1 yapar. Daha büyük tümörler abdusens, glossofaringeus, vagus sinirleri hatta daha alt kafa çiftlerine de bası yapabilmektedir (5-7). Tümörün cerrahi olarak eksizyonu sonrasında da iyatrojenik kraniyal sinirlerde hasar olabilmektedir. Büyük tümörlerde $(>2 \mathrm{~cm})$ komplikasyon oranı daha yüksek bildirilmektedir $(8,9)$. Akustik nörinom olgularında, trigeminal sinir tutulumuna bağlı göz kırpma refleksinde azalma, fasiyal sinir tutulumuna bağlı açıkta kalmaya bağlı oküler yüzey problemleri, abdusens sinir tutulumuna bağlı çift görme ve şaş1lık gibi oftalmolojik problemler ortaya çıkabilmektedir.

Biz bu yazımızda, akustik nörinoma bağlı trigeminal, abdusens, fasiyal ve vestibulokohlear sinir felçleri olan hastamızı tedavi ve takip sonuçlarıyla tartışmayı amaçladik.

\section{Olgu Sunumu}

Kırkaltı yaşında kadın hasta sağ gözünü kapatamama ve sağ gözde dişa bakamama şikayeti ile kliniğimize başvurdu. Hastanın hikayesinden 5 yıl önce Suriye'de akustik nörinom nedeniyle ameliyat geçirdiği 
öğrenildi. Ameliyatla ilgili detaylar öğrenilemedi. Hastanın değerlendirilen en iyi düzeltilmiş görme keskinliği Snellen harf eșeli ile sağ gözde 2 metreden parmak sayma düzeyinde iken sol gözde tamdi. Direkt ve indirekt 1ş1k refleksleri her iki gözde pozitifti, rölatif afferent pupilla defekti yoktu. Sikloplejik refraksiyon değerleri sağ göz için $+2,0$ aks $115^{\circ}$ sol göz için $+0,25+0,50$ aks 180 。 idi. Biyomikroskopik muayenesinde sol göz doğal olarak izlenirken sağ gözde korneada açıkta kalma keratopatisine bağlı korneal skar saptandi. Fundus muayenesinde her iki göz fundus bulguları doğaldı. Yapılan ortoptik muayenede Krimsky testi ile primer pozisyonda 80 prizma diyoptri (PD) sağ ezotropya mevcuttu ve sağa bakışta kayma daha da artmaktaydı. Sağ gözde dışa bakışta -5 kısıtl1lık vard1. Diğer göz hareketleri doğald1. (Şekil 1) Nöroloji bölümü tarafından yapılan ayrıntılı kraniyal sinir muayenesinde sağ göz kornea duyarlılığında azalma mevcuttu ve trigeminal sinir tutulumu olduğu düşünüldü. Bell fenomeni pozitif olarak saptanan hastanın sağ gözünü kapatamadığı görüldü. Ayrıca sağ gözde lagoftalmus vardı. Bu bulgularla sağ periferal fasiyal paralizi düşünüldü. (Şekil 2a ve $2 b)$ Sağ kulağı ile ișitme problemi olan hastanın vestibulokohlear sinirinin de etkilendiği düşünüldü. Yapılan beyin manyetik rezonans görüntülemesi sonucu, sağ serebellopontin açıda geçirilmiş cerrahiye bağlı bulgular izlenirken, kalmış tümör dokusu izlenmedi. Hastaya geçirilmiş akustik nörinom cerrahisine bağlı sağ trigeminal, abdusens, fasiyal ve vestibulokohlear sinir felci tanis1 konuldu.

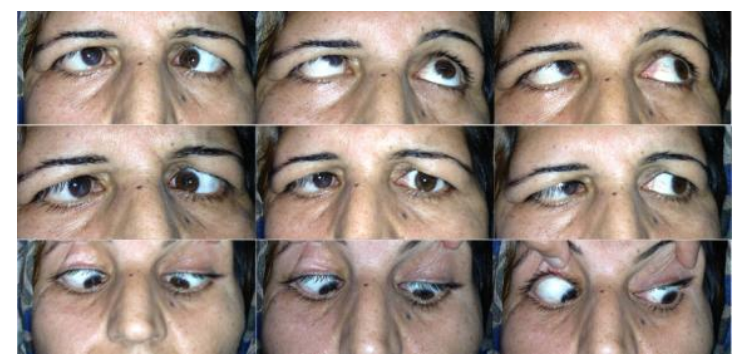

Şekil 1: Olgunun göz hareketleri. Primer pozisyonda geniş açllı sağ ezotropya ve sağ gözde dışa bakışta -5 kısıtlılık vardı. Diğer göz hareketleri genel olarak doğaldı

Durumu hakkında bilgi verilen hasta kozmetik açıdan rahatsız olduğunu ve sosyal ilişkilerinin etkilendiğini belirtti. Fasiyal sinir paralizisi bulgularını düzeltmek için orta yüz kaldırma ve

levator menteşe yöntemi ile levator geriletme ameliyatı yapıldı. Cerrahi teknikler kısaca şu şekildeydi:

Orta yüz kaldırma: Lateral kantotomi ve kantolizisle alt göz kapağı serbestleștirilip konjonktival yol ile orbita alt kenarına ulaşıldı. Periost alt orbita kenarının 4-5 $\mathrm{mm}$ alt1 hizasından tüm orbita kenarı boyunca ve lateralde zigomatik arka kadar kesildi. Daha sonra subperiostal diseksiyon gingival fornikse kadar ilerletilerek yanak dokusu serbestleștirildi. Periost ve orbiküler oküli altı yağ dokusundan, $3 / 0$ polipropilen sütür geçirilip orbita kenarına ve temporal fasyaya sütüre edilerek orta yüz kaldırma gerçekleştirildi. Alt kapağı yükseltmek için sert damak grefti alınarak konjonktivada yapılan kesi ve tars arasına sütüre edildi. Daha sonra lateral kantal askılama işlemi yapıldı.

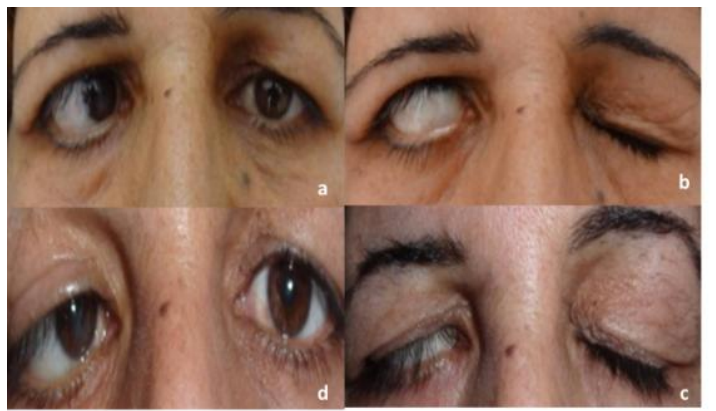

Şekil 2: a,b) Hastanın göz kapak ameliyatı öncesi gözü açıkken ve kapalıyken göz kapaklarının durumu. c,d) Kapak ameliyatı sonrası gözü açıkken ve kapalıyken göz kapaklarının durumu. Lagoftalmusta belirgin gerileme dikkati çekmektedir.

Levator menteşe prosedürü: Diğer göz kapağ 1 ile simetrik olacak şekilde sağ üst kapak kıvrımından insizyon hattı işaretlendi. Lokal anestezi için cilt altına lidocaine hidrokloridepinefrin $(1: 100,000)$ solüsyonu verildi. Cilt ve orbiküler kas kesisi yapıldıktan sonra orbital septum açılarak ve preaponörotik yağ dokusu retrakte edilerek Whitnall ligamentine kadar tüm levator aponörozu açığa çıkarıldı. (Şekil 3a) Levator aponörozu tarsa yapıștığı yerden ayrılarak Müller kası diseke edildi. (Şekil 3b). Aponörozun diş 1/3-1/2'si 5-6 mm genişlikte kesilerek bir flep oluşturuldu. (Şekil 3c,d) Bu flep aşağ doğru 90 derece döndürülerek tarsın üst kenarına $6 / 0$ vikril ile dikildi. (Şekil 3e) 


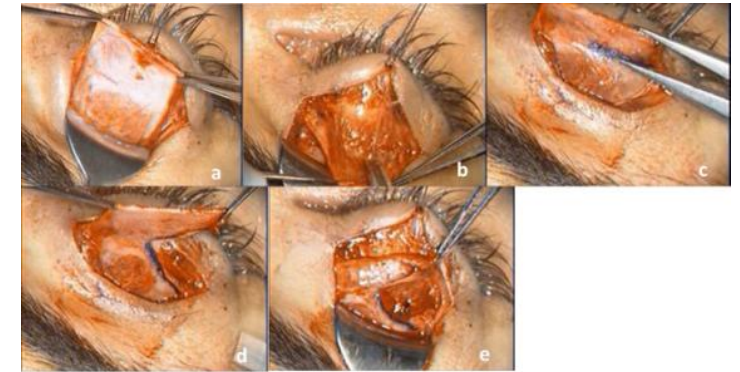

Şekil 3: Levator menteşe yöntemi ile levator geriletme ameliyatının basamakları. a,b) Müller kasından ayrılan levator aponörozun iç ve diş boynuzları forsepsle tutulmuş olarak görülüyor. c,d) Levator aponörozun alt kenarından bir flep hazırlanmaktadır. e) Hazırlanan flep tars üst kenarına sütüre edilmiştir.

Cilt kesisi, aponörozdan da geçecek şekilde derin 3 veya 4 ilave dikiş de olmak üzere 6/0 vikril ile dikildi. Topikal antibiyotik pomad uygulanarak kapatıldı. Ameliyat sonrası 48 saat buz uygulandi.

Hastanın ameliyat sonras1 3.ay kontrolünde kapak aralığ 1 belirgin olarak azalmış ve lagoftalmusu düzelmişti. (Şekil $2 \mathrm{c}$ ve $2 \mathrm{~d}$ ). Sağ gözündeki kaymadan da rahatsız olan hastaya Abdusens felci bulguları için Foster sütür ile Hummelsheim split tendon transpozisyonu ameliyatı yapıldı. Cerrahi kısaca şu şekildeydi: Hastanın să gözüne iç rektus kasına ayarlanabilir sütür ile geriletme ile birlikte, dış rektus kasina transpozisyon cerrahisi uygulandı. Alt ve üst rektusun diş yarıları Tillaux halkasına uygun olacak şekilde dış rektusun üst ve alt kenarına transpoze edildi ve Foster sütürleri kondu. Cerrahi sonrası ilk gün sol gözde dışa bakış kısıtlılığ -3 olarak değerlendirildi, primer pozisyonda Krimsky testi ile sağ gözde 15 PD hipotropya, sola bakışta 10 PD hipotropya ve 20 PD ezotropya mevcuttu. (Şekil 4) Sonrasında mülteci olan hasta ülkesine döndüğü için kontrollere

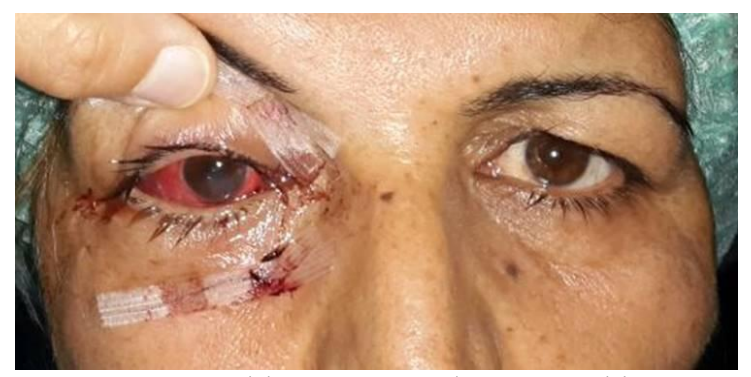

Şekil 4: Şaşılık ameyatından sonraki 1.gün görünümü. Primer pozisyonda sağ gözde hafif gelemedi.

hipotropya mevcut iken, ezotropya izlenmemektedir.

Tüm hasta bilgileri ve resimleri hastadan onam alınarak sunulmuştur.

\section{Tartışma ve Sonuç}

Çok sayıda kraniyal sinir felci gelişimi pek çok nörolojik ve sistemik hastalığın sonucu olarak ortaya çıkabilmektedir. Bunlar sarkoidoz, intrakraniyal kanamalar, menenjit ve kafa içi tümörler olarak sayılabilir. Serebellopontin açıda en sık görülen tümör olan akustik nörinom olgularında cerrahi öncesi ya da cerrahiye bağlı olarak sıklıkla vestibulokohlear sinir ve fasiyal sinir etkilenmektedir, nadiren trigeminal sinir, abdusens sinir ve daha alt kafa sinirlerin etkilendiği de bildirilmiştir $(6,10,11)$. Bizim olgumuzda tümör basisina ya da cerrahi sırasında oluşan sinir hasarına bağlı olarak 4 kraniyal sinirde paralizi izlendi. Trigeminal ve fasiyal sinirin hasarlanmasına bağl1 olarak her ne kadar hasta ameliyattan sonra göz damlalarını düzenli kullandığını söylese de hem kornea duyarlılığının azalmasına hem de gözün yeterli kapanamamasına bağlı keratopati gelişmiş ve hastanın görmesi 2 m'ye kadar düşmüştü. Mulhern ve ark özellikle 5.sinir hasarına bağlı korneal duyu kaybı ve 7 .sinir hasarına bağlı lagoftalmus olmasının görme kaybı açısından daha riskli olduğunu ve bu tarz hastalarm hayat boyu tedavi gereksinimi olduğunu belirtmişlerdir (10). Akustik nörinoma bağlı en çok etkilenen kraniyal sinir fasiyal sinirdir (12). $\mathrm{Bu}$ probleme bağl1 hastalar hem fonksiyonel anlamda hem de kozmetik anlamda sıkıntı çekebilmektedir. Akustik nörinoma bağlı nadiren abdusens paralizileri de bildirilmiştir $(5,6)$. Bu duruma bağlı çift görme ve şaşılık hastaları rahatsız edebilmektedir. Bizim olgumuzda keratopatiye bağlı sağ gözü az gördüğü için diplopi mevcut değildi. Olgumuzda ilave olarak işitme kaybı (vestibulokohlear sinir hasar1) ve kornea duyusunda azalma (trigeminal sinir hasarı) mevcuttu fakat hastanın en önemli yakınması kozmetik ve sosyal ortamlarda rahatsizlıktı. Hasta fasiyal paraliziye bağlı gözünü kapatamama ve yüzünde mimik kasların çalışmamasından ve sağ gözdeki şaşılıktan rahatsizd. Bu nedenle olgumuza fasiyal sinir hasarına bağlı bulguları düzeltmek için levator menteşe yöntemi ile levator geriletme ve yüz Adress for correspondence: Yard. Doç. Dr. Tuğba Göncü. Harran Üniversitesi Tıp Fakültesi, göz Hastalıkları Anabilim Dalı, yenişehir Kampüsü, 63320, Şanlıurfa 63300 Şanlıurfa Türkiye

e-mail: drtgoncu@hotmail.com

Available at www.actaoncologicaturcica.com

Copyright $\odot$ Ankara Onkoloji Hastanesi 
kaldırma cerrahisi yapıldı. Sonrasında da geniş açılı ezotropyası ve dişa bakış kısıtlılı̆g için aynı göze ayarlanabilir sütür ile medial rektus geriletme ve Foster sütür ile Hummelsheim split tendon transpozisyonu uyguland. Ameliyat sonrası erken dönemde tatmin edici sonuç alındı ve hasta görünümünden memnun olduğunu belirtti.

Akustik nörinom hem ameliyat öncesi hem de ameliyat sonrasinda göz fonksiyonlarını ilgilendiren kraniyal sinir hasarları ile yakından ilişkili bir problemdir. $\mathrm{Bu}$ nedenlerle akustik nörinom takibinde ve tedavisinde göz doktorları mutlaka sürece dahil olmalıdır. Özellikle geri dönüşümsüz görmeyi azaltan kornea problemleri oluşmadan engellenmeli, hastaların hayat kalitesini azaltan kozmetik yakınmalarına çözüm aranmalıdır.

\section{Çıkar Çatışması: Yok}

\section{Kaynaklar}

1. Tos M, Charabi S, Thomsen J. Clinical experience with vestibular schwannomas: epidemiology, symptomatology, diagnosis, and surgical results. Eur Arch Otorhinolaryngol. 1998;255:1-6

2. Nadol JB. Cerebellopontine angle tumors. In: Nadol BN, Schuknecht HF, eds. Surgery of the ear and temporal bone. New York: Raven Press, Ltd;1993:391-412
Mertol T, Güner M, Atabay H, Diren B, Pırnar T. Akustik nörinomlarda Manyetik rezonans görüntüleme. Türk Nöroşirürji Dergisi. 1990;1:157161

3. Johnson EW. Auditory test results in 500 cases of acoustic neuroma. Arch Otolaryngol 1977;103:152-8

4. Ro LS, Chen ST, Tang LM, Wei KC. Concurrent trigeminal, abducens, and facial nerve palsies presenting as false localizing signs: case report. Neurosurgery. 1995;37:322-5

5. Rogers NK, Brand CS. Acoustic neuroma and the eye. Br J Neurosurg. 1997;11:292-7

6. Uzun C. Akustik nörinom ve travmatik fasiyel sinir paralizilerinde Tos ve thomsen'in translabrinter yaklaşımı: Olgu sunumları. Balkan medical Journal 2009;26:159-162

7. Sanna M, Taibah A, Russo A, Falcioni M, Agarwal M: Perioperative complications in acoustic neuroma (vestibular schwannoma) surgery. Otol Neurotol 2004;25:379-386

8. Chen Z, Prasad SC, Di Lella F et al. The behavior of residual tumors and facial nerve outcomes after incomplete excision of vestibular schwannomas. J Neurosurg. 2014;120:1278-87

9. Mulhern MG, Aduriz-Lorenzo PM, Rawluk D, Viani L, Eustace P, Logan P. Ocular complications of acoustic neuroma surgery. $\mathrm{Br} \quad \mathrm{J}$ Ophthalmol. 1999;83:1389-92

10. Bosch MM, Boltshauser E, Harpes P, Landau K. Ophthalmologic findings and long-term course in patients with neurofibromatosis type 2. Am J Ophthalmol. 2006;141:1068-1077

11. Falcioni M, Fois $P$, Taibah $A$, Sanna M: Facial nerve function after vestibular schwannoma surgery. Clinical article. J Neurosurg 2011;115:820-826 